Emerging therapy review

\title{
K-111: the emerging evidence for its potential in the treatment of the metabolic syndrome
}

\author{
Margaret Duggan-Keen
}

Core Medical Publishing, Knutsford, UK

\begin{abstract}
Introduction: Prevalence of the metabolic syndrome has increased dramatically in recent years. Optimal patient care demands a multifaceted approach, with many individuals requiring several therapies to minimize the significant associated cardiovascular burden. The need for novel agents in the management of the metabolic syndrome is emphasized by the current lack of drugs to treat insulin resistance, one of the major components of the metabolic syndrome that has several deleterious consequences.

Aims: The objective of this review is to assess the emerging evidence for the potential use of $\mathrm{K}-111$ in treatment of the metabolic syndrome.

Emerging evidence: $\mathrm{K}-111$ is a peroxisome proliferator-activated receptor (PPAR)-alfa agonist that, in preclinical studies, has shown efficacy in improving insulin resistance, reducing bodyweight, and ameliorating atherogenic dyslipidemia. Preliminary evidence suggests that toxicity and adverse events are low.

Profile: The improvements in obesity and insulin resistance, together with other beneficial effects following activation of PPAR alfa by K-111 in preclinical models, are encouraging and offer several potential advantages over currently available therapies for patients with the metabolic syndrome. However, $\mathrm{K}-111$ is at an early stage of development and establishment of its role will require full analysis of clinical trials carefully designed to determine its overall benefits in this increasingly important disease area.
\end{abstract}

Key words: BM 17.0744, cardiovascular diseases, insulin resistance, K-111, metabolic syndrome X, PPAR alfa

\section{Core emerging evidence summary for $\mathrm{K}-111$ in the metabolic syndrome}

\begin{tabular}{|ll|}
\hline Outcome measure & Emerging evidence \\
\hline Lipid profile & Substantial amelioration of the atherogenic lipid profile in all studies \\
Insulin resistance & Markedly improved insulin sensitivity in all studies \\
Obesity & No evidence of adipogenesis \\
& Beneficial effects on bodyweight and a trend for reduced food intake observed in the majority of studies \\
\hline
\end{tabular}




\section{Scope, aims, and objectives}

K-111 (F. Hoffmann-La Roche), formerly known as BM 17.0744 [2,2-dichloro-12-(p-chlorophenyl)-dodecanoic acid], is a peroxisome proliferator-activated receptor (PPAR)-alfa agonist. $\mathrm{K}-111$ is an insulin sensitizer and is currently undergoing phase II clinical trials. Low insulin sensitivity (insulin resistance) is a major component of the metabolic syndrome. This review provides an overview of the metabolic syndrome and examines the emerging evidence of a role for $\mathrm{K}-111$ in the treatment of this condition.

\section{Methods}

The English language literature was searched in July 2005 in the following databases. The search terms were "K-111," "K111," and "BM 17.0744," with minor variations in syntax applied to some databases to resolve inappropriate data retrieval. No date cut-offs were used except where stated.

- PubMed, http://www.ncbi.nlm.nih.gov/entrez

- EMBASE, http://www.datastarweb.com

- BIOSIS Previews, http://www.datastarweb.com

- York University Centre for Reviews and Dissemination databases: Database of Abstracts of Reviews of Effects (DARE); Health Technology Assessment (HTA); National Health Service Economic Evaluation Database (NHSEED), http://www.york.ac.uk/inst/crd/crddatabases.htm

- Cochrane Database of Systematic Reviews (CDSR), http://cochrane.org/index0.htm

- Clinical Evidence (BMJ), http://clinicalevidence.com

- National Guideline Clearing House, http://www.guideline.gov

- Clinical trial registers, http://www.clinicaltrials.gov, http://clinicalstudyresults.com, http://controlled-trials.com

A total of 40 articles were retrieved (38 full papers and two abstracts). Searching of abstracts presented at congresses of the following societies did not identify any additional abstracts: International Diabetes Federation (IDF) and European Association for the Study of Diabetes (2002-2004); American Diabetes Association (2003-2005); American Heart Association (2004); European Atherosclerosis Society $(2004,2005)$; European Society for Cardiology (2003).

\begin{tabular}{|c|c|c|}
\hline \multirow[t]{2}{*}{ Category } & \multicolumn{2}{|c|}{ Number of records } \\
\hline & Full papers & Abstracts \\
\hline Initial search & 38 & 2 \\
\hline records excluded & 29 & 0 \\
\hline records included & 9 & 2 \\
\hline
\end{tabular}

A total of 29 papers were excluded because they did not specifically concern $\mathrm{K}-111$, or had no direct relevance to the metabolic syndrome, or were general review papers, leaving nine papers and two abstracts for evaluation (Table 1). There was no clinical evidence available and all 11 publications included in the evidence base were outcomes from preclinical studies.

\section{Disease overview}

The metabolic syndrome is defined by the disproportionate clustering of several risk factors for cardiovascular disease (CVD) within individuals, leading to a significant increase in associated morbidity and mortality. Also referred to as syndrome $X$, the deadly quartet, or dysmetabolic syndrome $X$, the metabolic syndrome has a complex pathophysiology. Major components recognized are atherogenic dyslipidemia, hypertension, central obesity, insulin resistance with or without glucose intolerance or diabetes, and proinflammatory and prothrombotic states (Reaven 1988; Sakkinen et al. 1999; Grundy et al. 2004a; Eckel et al. 2005).

Several sets of clinical criteria have been put forward for defining the metabolic syndrome (WHO 1999; NCEP ATP III 2001; Balkau et al. 2002; Einhorn et al. 2003; Grundy et al. 2004a; IDF 2005a). Although there is general agreement as to the most important components of the syndrome, each definition varies in the precise thresholds and specific factors that are to be met in making a positive diagnosis. The most frequently used criteria have been those from the World Health Organization (WHO) and National Cholesterol Education Program Adult Treatment Panel III (NCEP ATP III) (Table 2), with the latter considered the more easily implemented for routine clinical use. However, the IDF consensus, which is the most recent definition (IDF 2005a), considers central obesity to be a necessary requirement (Table 2) whereas this factor is not mandatory for either the NCEP ATP III or WHO recommendations.

Both prospective and retrospective studies have indicated that the risks of cardiovascular morbidity and mortality are increased in patients with the metabolic syndrome versus those without the syndrome (Isomaa et al. 2001; Lakka et al. 2002a; Cohen et al. 2003; L'Italien et al. 2003; Girman et al. 2004; Hu et al. 2004; Malik et al. 2004; Ninomiya et al. 2004). In the prospective Kuopio Heart Study of middle-aged men, the risks of death from coronary heart disease, CVD or total mortality in those with the WHO-defined metabolic syndrome were increased by 2.9-3.3, 2.6-3.0, and 1.9-2.1, respectively (Lakka et al. 2002a). Subanalyses of patients included in the landmark statin trials have similarly identified increased risks of total and cardiovascular mortality (L'Italien et al. 2003; Girman et al. 2004).

\section{Disease pathophysiology}

Although there is general agreement as to the main components of the metabolic syndrome, the complex interactions between these factors are not well understood. Indeed, a recent statement by the American Diabetes Association and the European Association for the Study of Diabetes, while not disputing the clustering of CVD risk factors within individuals, has questioned 
Table 2 | Criteria for definition of the metabolic syndrome

\begin{tabular}{|c|c|c|c|}
\hline & WHO 1999 & NCEP ATP III 2001 & IDF 2005a \\
\hline Requirement: & $\begin{array}{l}\text { Impaired glucose regulation or diabetes } \\
\text { and/or insulin resistance plus } \geq 2 \text { of the } \\
\text { following: }\end{array}$ & $\geq 3$ of the following: & $\begin{array}{l}\geq 3 \text { of the following, one of which must be } \\
\text { central obesity: }\end{array}$ \\
\hline Central obesity & $\begin{array}{l}\mathrm{BMI}>30 \mathrm{~kg} / \mathrm{m}^{2} \text { and } / \text { or waist-to-hip ratio: } \\
\mathrm{men}>0.90 \text {; women }>0.85\end{array}$ & $\begin{array}{l}\text { Waist circumference: men }>102 \mathrm{~cm} \text {; } \\
\text { women }>88 \mathrm{~cm}\end{array}$ & $\begin{array}{l}\text { Waist circumference: } \text { men } \geq 94 \mathrm{~cm} \text {; } \\
\text { women } \geq 80 \mathrm{~cm}\end{array}$ \\
\hline Fasting glucose & & $\geq 6.1 \mathrm{mmol} / \mathrm{L}(110 \mathrm{mg} / \mathrm{dL})$ & $\geq 5.6 \mathrm{mmol} / \mathrm{L}(100 \mathrm{mg} / \mathrm{dL})$ \\
\hline Triglycerides & $\geq 1.7 \mathrm{mmol} / \mathrm{L}(150 \mathrm{mg} / \mathrm{dL})^{\mathrm{a}}$ & $\geq 1.7 \mathrm{mmol} / \mathrm{L}(150 \mathrm{mg} / \mathrm{dL})$ & $\geq 1.7 \mathrm{mmol} / \mathrm{L}(150 \mathrm{mg} / \mathrm{dL})^{\mathrm{a}}$ \\
\hline \multirow[t]{2}{*}{ HDL-C } & Men: <0.9 mmol/L (35 mg/dL) & Men: <1.0 mmol/L (40 mg/dL) & Men: $<1.03$ mmol/L (40 mg/dL) \\
\hline & Women: <1.0 mmol/L (39 mg/dL) & Women: <1.3 mmol/L (50 mg/dL) & Women: $<1.29 \mathrm{mmol} / \mathrm{L}(50 \mathrm{mg} / \mathrm{dL})$ \\
\hline Microalbuminuria & $\begin{array}{l}\text { Urinary albumin excretion rate } \geq 20 \mu \mathrm{g} / \mathrm{min} \\
\text { or albumin : creatinine ratio } \geq 30 \mathrm{mg} / \mathrm{g}\end{array}$ & & \\
\hline Blood pressure & $\geq 140 / 90 \mathrm{mmHg}$ & $\geq 130 / 85 \mathrm{mmHg}$ & $\geq 130 / 85 \mathrm{mmHg}^{\mathrm{a}}$ \\
\hline
\end{tabular}

whether there is sufficient evidence to warrant the designation of "syndrome" (Kahn et al. 2005). However, it is thought that the two most critical components are obesity and insulin resistance.

\section{Obesity}

Obesity is a major underlying cause of the metabolic syndrome, affecting many of its individual components, including blood pressure, cholesterol, triglycerides (TG), and insulin resistance. Obesity is defined on the basis of body mass index (BMI); however, definitions of the metabolic syndrome use measures of central obesity rather than BMI on the basis that central obesity (in particular visceral fat accumulation) is a more accurate measure of cardiovascular risk than overall excess bodyweight (Prineas et al. 1993; Rimm et al. 1995; Lakka et al. 2002b). Abdominal obesity increases the risk of type 2 diabetes, atherogenic dyslipidemia, and hypertension (Després et al. 2001).

\section{Insulin resistance}

The initial description of the metabolic syndrome as centered on insulin resistance emphasizes the important contribution of this component. Insulin resistance is recognized as a precursor for diabetes, which is well established as conferring higher CVD risk. Approximately $65 \%$ of patients with diabetes die from heart disease or stroke (CDC 2005). Overabundance of circulating free fatty acids as a result of increased fat mass, particularly in deep subcutaneous and visceral adipose depots, and large adipocytes that are resistant to the ability of insulin to suppress lipolysis, contribute to the development of insulin resistance and compensatory hyperinsulinemia. Free fatty acids inhibit glucose metabolism in skeletal muscle and stimulate gluconeogenesis in the liver. Levels of adiponectin are decreased, reducing its insulinsensitizing effect. Although there is a correlation between insulin resistance and increasing body fat, the relationship is complex; not all obese patients are insulin resistant, and a broad range of insulin sensitivities are observed at any given level of body fat (Abbasi et al. 2002). Insulin resistance leads to a wide range of deleterious metabolic changes, including the development of glucose intolerance, overt diabetes, hypertriglyceridemia, and hypertension.

\section{Dyslipidemia}

The pattern of atherogenic dyslipidemia in patients with the metabolic syndrome is similar to that in patients with diabetes and is a result of insulin resistance, with a number of mediators involved (e.g. hepatic lipase, lipoprotein lipase, cholesterol ester transfer protein) (Ayyobi \& Brunzell 2003). The effect of increasing free fatty acid flux to the liver leads to increased production of apolipoprotein B-containing, TG-rich, very-low-density lipoproteins (VLDL). TG levels are increased and there is a reduction in high-density lipoprotein cholesterol (HDL-C), accompanied by other abnormalities including increased remnant lipoproteins, elevated apolipoprotein B, small dense LDL particles, and small dense HDL particles. All these lipid disturbances are established as independent risk factors for CVD. Although raised LDL-C levels are not a diagnostic feature of the metabolic syndrome, many patients also have this additional CVD risk factor.

\section{Hypertension}

Hypertension has many causes that are unrelated to the metabolic syndrome. Nevertheless, elevated blood pressure is common in obese individuals and also occurs frequently in association with insulin resistance. Numerous outcomes trials have established hypertension as a major risk factor for CVD.

\section{Proinflammatory state}

The production by adipose tissue of proinflammatory cytokines, such as tumor necrosis factor and interleukin (IL)-6, is increased in patients with the metabolic syndrome (Grundy et al. 2004b) and 
may lead to inappropriate inflammatory cascades and subsequent tissue destruction. In contrast, levels of adiponectin, which enhances insulin sensitivity and has an inhibitory effect at several stages of the inflammatory process (Lee \& Pratley 2005), are decreased (Matsuzawa et al. 2004). In addition, levels of Creactive protein (CRP), a marker of inflammation that is a strong independent indicator of incident CVD, are often elevated in patients with the metabolic syndrome (Fröhlich et al. 2000; Mora et al. 2003; Ridker et al. 2003), with a marked correlation between CRP levels and the number of metabolic syndrome components present (Fröhlich et al. 2000; Ridker et al. 2003).

\section{Prothrombotic state}

An unfavorable balance between prothrombotic and fibrinolytic factors, leading to a hypercoagulable state, is another feature of the metabolic syndrome (Nieuwdorp et al. 2005). Increased levels of clotting factors and inhibition of the fibrinolytic pathway are accompanied by greater platelet aggregability, all of which increase the risk of thrombotic events. Plasma levels of plasminogen activator inhibitor (PAl)-1 (a marker of decreased fibrinolytic capacity) and fibrinogen may be raised. Depressed plasmin levels may enhance the progression of atherosclerosis in individuals with hyperinsulinemia or glucose intolerance (Sakkinen et al. 1999).

\section{Epidemiologic profile}

Both genetic and environmental factors determine the prevalence of the metabolic syndrome and its individual components. In addition, estimates of the prevalence of the metabolic syndrome vary with the different criteria used for its definition and with the population demographics of individual studies. Comparison of the NCEP ATP III and WHO criteria in the National Health and Nutrition Examination Survey (NHANES) III in the United States provided age-adjusted prevalences of 23.9 and $25.1 \%$, respectively, with concordance in $86.2 \%$ of subjects although there were marked differences in certain ethnic groups (Ford et al. 2003). In contrast, applying the WHO and IDF criteria to a Greek population revealed markedly different values of 24.5 and $43.4 \%$, respectively, causing the authors to question the validity of the less demanding IDF definition (Athyros et al. 2005). However, there is general agreement that the overall prevalence is projected to increase dramatically in the future. This is attributable to several factors.

Firstly, the metabolic syndrome is more common in older individuals, and greater longevity means that the elderly contribute to an increasingly large proportion of populations. In the NHANES survey in the USA, prevalences ranged from $6.7 \%$ in those aged $20-29$ years, to $43.5 \%$ in the $\geq 60$ years age group (Ford et al. 2002). Second, the two components that many would agree are central to development of the metabolic syndrome, obesity and insulin resistance, are on the increase.

Obesity has become a global problem and is no longer restricted to developed countries. Recent data indicate that more than a billion adults are classified as overweight $\left(\mathrm{BMI} \geq 25 \mathrm{~kg} / \mathrm{m}^{2}\right)$, and the number of obese $\left(\mathrm{BMI} \geq 30 \mathrm{~kg} / \mathrm{m}^{2}\right.$ ) people is $>300$ million (WHO
2003; James et al. 2004), reflecting at least a doubling in the prevalence of obesity over less than two decades. Furthermore, there has been an accompanying increase in childhood obesity (James et al. 2004). Higher BMls are correlated with a greater prevalence of the metabolic syndrome (Park et al. 2003).

The number of individuals with diabetes (171 million in 2000) is projected to increase to 366 million by 2030 , equivalent to a global prevalence of $4.4 \%$ (Wild et al. 2004). The burden of diabetes is well established, and many patients die from cardiovascular complications. Type 2 diabetes, which has previously been considered a disease of adulthood, is now occurring in children in parallel with sedentary lifestyles and increasing obesity (Drake et al. 2002; Kaufman 2002). It is not surprising, therefore, that the metabolic syndrome is also being detected at an increasing frequency in children and adolescents (Falkner et al. 2002; de Ferranti et al. 2004; Duncan et al. 2004; Weiss et al. 2004).

\section{Burden of disease}

There is no doubt that the metabolic syndrome impacts significantly on economic and healthcare resources. Raised BMI, high cholesterol and high blood pressure are among the top five leading risk factors for the burden of disease in developed countries (WHO 2002b). Obesity is killing about 220000 men and women every year in the USA and Canada alone, and about 320000 men and women in 20 countries of Western Europe (WHO 2002b). Crude estimates of the costs of obesity and its comorbidities amount to $7 \%$ of total healthcare budgets in some countries (James et al. 2004). Death due to diabetes is mainly due to cardiovascular complications and many are premature, when the people concerned are making an economic contribution to society. Direct healthcare costs range from 2.5 to $15 \%$ of annual healthcare budgets, depending on prevalence and sophistication of treatment. The estimated cost of treating diabetes in the USA in 1997 was \$US44 billion (WHO 2002a).

A considerable proportion of coronary heart disease morbidity and mortality is not accounted for by traditional risk-prediction formulae. This may explain why an increased risk of CVD is associated with the metabolic syndrome even after traditional risk factors are accounted for (Lakka et al. 2002a). However, it is debatable whether adding the risk factors for metabolic syndrome may be of use in improving the accuracy of CVD risk using other methods, such as the Framingham algorithm (Wilson et al. 1998; Girman et al. 2004; Stern et al. 2004). Furthermore, the merit of adding CRP as a clinical criterion for the metabolic syndrome and/or the development of a CRP-modified coronary risk score is an important area for debate (Ridker et al. 2004). Recently, it has been noted that some of the cut-off points used to define the metabolic syndrome are set arbitrarily, and categorizing patients as candidates for treatment on this basis is not necessarily appropriate (Kahn et al. 2005). Consistent with this, the vascular event risk for patients with the IDF-defined metabolic syndrome using the Framingham risk engine has been estimated as $6.1 \%$, significantly lower $(P<0.0001)$ compared with an estimate of $11.3 \%$ for patients with the NCEP ATP III-defined metabolic syndrome (Athyros et al. 2005). However, all chronic progressive 
diseases are marked by cut-off points and it is not uncommon for these to vary within a single condition. Some guidelines recommend conservative cut-off points whereas others advocate more stringent levels for diagnosis on the basis that earlier treatment is potentially better. Variations in disease definitions also reflect the interests and concerns of different professional bodies; for the metabolic syndrome this includes diabetologists, cardiologists, and epidemiologists.

\section{Current therapy options}

There are currently no evidence-based guidelines solely aimed at treating patients with the metabolic syndrome. However, the American Heart Association, the National Heart, Lung, and Blood Institute, and the American Diabetes Association have issued a joint scientific statement on the management of the metabolic syndrome (Grundy et al. 2004b). Advice on treating the syndrome or its components are included in obesity, hypertension, diabetes, and CVD guidelines (National Heart, Lung, and Blood Institute 1998; WHO 1999; NCEP ATP III 2001; De Backer et al. 2003; ADA 2004; Klein et al. 2004; IDF 2005b). In addition, the IDF have included treatment advice in their recent consensus definition of the metabolic syndrome (IDF 2005a).

Management of the metabolic syndrome is aimed at minimizing the risk of developing CVD or overt diabetes. However, the risk is not uniform for all patients and it is recommended that 10-year CVD risk assessments (NCEP ATP III 2001; Conroy et al. 2003) are carried out for all patients to determine their optimal treatment strategy (Eckel et al. 2005). Whether the inclusion of less traditional risk factors (e.g. insulin resistance, apolipoprotein B levels) will improve CVD risk assessment has not been clarified.

Advice is consistent in advocating lifestyle changes (e.g. reducing obesity, increasing physical activity, and reducing saturated fat intake) as the first-line treatment option for the metabolic syndrome since these simultaneously improve many symptoms (e.g. lowering of blood pressure, improvements in insulin resistance, and a less-atherogenic lipid profile). However, pharmacologic intervention is frequently required to enable patients to achieve advocated target levels for individual risk factors. The current approach is to address each risk factor as a separate entity and prescribe several pharmacologic therapies in parallel; nevertheless, it is becoming apparent that the pleiotropic characteristics of certain agents provide additional benefits beyond their principal therapeutic action. Recognition of the potential benefits of single agents to induce multiple risk reduction reinforces the concept that the individual symptoms of the metabolic syndrome are the end result of a complex series of interactions and should not be considered in isolation.

\section{Antihypertensive agents}

Although guidelines for the management of hypertension vary in the exact blood pressure levels at which pharmacologic intervention is recommended, they are unanimous in recognizing the need for more stringent targets in individuals with comorbidities such as diabetes and preexisting CVD (Chobanian et al. 2003; ESH/ESC 2003; Whitworth 2003; Williams et al. 2004). No agents in particular are specified for treating patients with the metabolic syndrome but many patients will require combination therapy to attain blood pressure goals.

\section{Lipid-modifying agents with pleiotropic effects}

\section{Statins}

It is well established that statins are the most effective agents for lowering LDL-C levels; they also raise HDL-C levels, lower TG, and reduce the number of apolipoprotein $B$-containing lipoproteins. Patients with features of the metabolic syndrome have been included in some of the major outcomes trials of statins that have shown these agents to be of significant benefit in reducing cardiovascular morbidity and mortality. Subgroup analyses of these and of studies where changes in lipid levels were the primary endpoint have indicated that the benefits extend to patients with the metabolic syndrome (Ballantyne et al. 2001; Hunninghake et al. 2003; Sattar et al. 2003). In addition to their beneficial effects on the lipid profile, other pleiotropic effects of statins have been identified, including improving endothelial dysfunction, reducing inflammation, and antithrombotic properties (Bellosta et al. 2000; Liao 2002; Sowers 2003).

\section{PPAR-alfa agonists}

Fibric acid derivatives (fibrates) are PPAR-alfa agonists and have been shown to beneficially affect the atherogenic profile. They are especially effective at raising HDL-C levels and lowering TG and their ability to reduce cardiovascular morbidity and mortality has been established in outcomes trials such as the Veterans Affairs HDL Intervention Trial (VA-HIT; Rubins et al. 1999) and the Helsinki Heart trial (Frick et al. 1987). As with the statins, evidence for the beneficial effects of fibrates on cardiovascular outcomes in patients with the metabolic syndrome is limited to retrospective subanalyses. In the VA-HIT trial, the greater reduction in cardiovascular events with gemfibrozil in subjects with insulin resistance than in those without, despite the smaller improvements in HDL-C and TG in the former group, supports the broader benefits of PPAR-alfa agonists that are lipid-independent (Robins et al. 2003). Similarly, in the Helsinki Heart Study, gemfibrozil reduced coronary risk mainly in overweight subjects with additional risk factors related to insulin resistance (Tenkanen et al. 1995). The most dyslipidemic group (TG $>2.3 \mathrm{mmol} / \mathrm{L}$ and LDL-C/HDL-C ratio $>5$ ) benefited most from gemibrozil treatment (Manninen et al. 1992). In the Bezafibrate Infarction Prevention Study, bezafibrate reduced the incidence of myocardial infarction in patients with the metabolic syndrome, with a marked strengthening of cardiac mortality reduction in patients with 4-5 metabolic syndrome risk factors (Tenenbaum et al. 2005).

PPAR-alfa agonists may also have important nonlipid actions including antiinflammatory, insulin-sensitizing, and vasoprotective actions (Berger et al. 2005; Tsimihodimos et al. 2005). For example, after 3 months of fenofibrate therapy, insulin resistance was reduced in patients with dyslipidemia and the metabolic syndrome (Wysocki et al. 2004). 


\section{Other lipid-modifying agents}

Niacin has beneficial effects on several aspects of atherogenic dyslipidemia and the HDL Atherosclerosis Treatment Study (HATS) showed that in combination with simvastatin, it augments the regression of proximal coronary stenosis and reduces the frequency of cardiovascular events in patients with low HDL-C levels and many other features of the metabolic syndrome (Brown et al. 2001). Inhibitors of cholesterol ester transfer protein (e.g. torcetrapib) currently in development may also be useful either alone or in combination with statins in patients with low HDL-C (Brousseau et al. 2004).

\section{Treating insulin resistance and type 2 diabetes}

Weight reduction and increased physical activity are the initial strategy for reducing insulin resistance. Treatment with biguanides and thiazolidinediones reduces insulin resistance and prevents or delays the onset of type 2 diabetes in patients with prediabetes (elevated fasting and/or postload glucose levels) (Buchanan et al. 2002; Knowler et al. 2002; Durbin 2004). Metformin is well established as a treatment for type 2 diabetes (UKPDS 34 1998). In the Diabetes Prevention Program, both lifestyle intervention and metformin therapy reduced the development of the metabolic syndrome (Orchard et al. 2005).

The more recently introduced thiazolidinediones are insulin sensitizers that stimulate PPAR gamma, leading to insulinresponsive proteins (Yki-Järvinen 2004). A study comparing the effect of pioglitazone, metformin, and a sulfonylurea on the metabolic syndrome and its components in patients with poorly controlled type 2 diabetes showed that although all agents significantly decreased the proportion of patients with the metabolic syndrome, pioglitazone, in addition to improving blood glucose control, had the greatest beneficial effects on blood pressure and TG and HDL-C levels (Rajagopalan et al. 2005).

Clearly, patients who have already developed diabetes should be treated in accordance with diabetes-specific recommendations (ADA 2004; IDF 2005b). For example, it is well established that good glycemic control is beneficial in preventing complications of diabetes (UKPDS 33 1998).

\section{Prothrombotic and proinflammatory states}

Low-dose aspirin is recommended for all patients with CVD. However, there is no evidence base for its role in primary prevention of CVD, even in those with type 2 diabetes. Statins have the potential to ameliorate the prothrombotic state by mechanisms that include reducing platelet aggregation and promoting fibrinolytic activity through the reduction of PAI-1 levels (Rosenson \& Tangney 1998; Liao 2002; Sowers 2003).

Strategies to reduce the underlying causes of inflammation in patients with the metabolic syndrome are limited to the pleiotropic effects of statins and fibrates (see above). In addition, thiazolidinediones have been reported to reduce levels of CRP (Nesto 2004).

\section{Unmet needs}

The complex pathophysiology underlying the metabolic syndrome requires the combination of different agents with divergent modes of action, as discussed above. This necessitates polypharmacy for most patients, with the potential for unwanted drug-drug interactions and associated adverse events (e.g. rhabdomyolysis following some statin-fibrate combinations) as well as poor adherence to medication due to complicated regimens. The introduction of drugs with modes of action against the "root causes" of the metabolic syndrome that lead to concomitant improvements in multiple aspects of the metabolic syndrome would clearly be of benefit to both patients and physicians, as well as impacting favorably on the economic burden. Although there is still room for improvement in antihypertensive and lipid-modifying therapies, it is other aspects of the metabolic syndrome such as insulin resistance and inflammation where there is the greatest potential for better treatment. The requirement for compounds that enhance insulin sensitivity is only partially fulfilled by thiazolidinediones. Thiazolidinediones have significant antidiabetic efficacy but their use is associated with adverse events including hemodilution, edema, adipogenesis, weight gain, toxic effects on the liver, and carcinogenic potential (Yki-Järvinen 2004). The results of the first outcomes study with thiazolidinediones, the PROspective pioglitAzone Clinical Trial In macroVascular Events (PROactive), were released in September 2005. In high-risk patients with type 2 diabetes, pioglitazone reduced the composite of all-cause mortality, nonfatal myocardial infarction, and stroke (PROactive Steering Committee 2005). However, no outcomes studies with thiazolidinediones in patients with the metabolic syndrome are available. Similarly, although a reduction in some cardiovascular endpoints were observed with metformin in obese patients with diabetes (UKPDS 34 1998), to date there are no CVD endpoint trials with metformin in patients with the metabolic syndrome. There are also dose-limiting toxic effects of metformin.

The pleiotropic effects of statins and fibrates that lead to improvements on nonlipid variables are not well clarified. Fibrates are relatively nonspecific ligands of PPAR alfa and have weak affinity, requiring high doses for efficacy. PPAR alfa plays a role in the inflammatory response at the vascular, splenic, and hepatic levels. Its antiinflammatory actions include inhibiting IL-1-induced IL-6 secretion, decreasing the expression of adhesion molecules on endothelial cells, and repressing the expression of certain acute-phase proteins in the liver (reviewed by Delerive et al. 2001). These observations are consistent with the amelioration of inflammation seen following administration of fibrates to patients with atherosclerosis or with hyperlipoproteinemia (Madej et al. 1998; Staels et al. 1998).

\section{Drug review}

With increasing knowledge of PPAR-alfa structure and function, specifically designed PPAR-alfa activators that have the potential for increased efficacy, potency and selectivity, and decreased adverse events are being developed, with several structurally distinct compounds under consideration (Miyachi 2004). K-111 is 
one such compound. Phase II trials of $\mathrm{K}-111$ are currently underway in Europe, the USA, and Japan, but no information is available regarding the trial design, the type of patients included, or the endpoints of the study, nor are there any published clinical data. As discussed below, properties of $\mathrm{K}-111$ that have been assessed in preclinical studies include its effects on the lipid profile, cardiac metabolism, bodyweight, and hyperinsulinemia. For $\mathrm{K}-111$ to prove a viable addition to currently available treatments for the metabolic syndrome, clinical studies need to demonstrate beneficial effects on all of these variables that are at least equal to those of other agents aimed at individual disease components and preferably with a lower rate of adverse events. Furthermore, determining the impact of $\mathrm{K}-111$ on less-welldefined aspects of the metabolic syndrome such as inflammation (e.g. by measuring CRP levels) will provide information that distinguishes it from other agents.

\section{Preclinical evidence}

$\mathrm{K}-111$ has been evaluated in mice, rats, guinea pigs, dogs, and nonhuman primates. Studies have included various rodent models of diabetes, rhesus monkeys with a metabolic syndrome phenotype with different genetic backgrounds, and healthy animals.

\section{Lipid profile}

All studies have demonstrated an improvement in serum hypertriglyceridemia with K-111 administration (Meyer et al. 1999; Pill \& Kühnle 1999; Pill \& Meyer 1999; Bodkin et al. 2003a,b; Schäfer et al. 2004; Ortmeyer et al. 2005). For example, sequential administration of $\mathrm{K}-111$ at doses of 1,3 , and $10 \mathrm{mg} / \mathrm{kg}$ per day ( 4 weeks for each dose) to obese rhesus monkeys reduced TG by 30,50 , and $53 \%$, respectively (Bodkin et al. 2003a). The levels of other lipid variables that are often abnormal in patients with the metabolic syndrome, such as large VLDL fractions and HDL-C and its subfractions, were also improved with $\mathrm{K}-111$ treatment in obese rhesus monkeys but reductions in serum cholesterol were restricted to rodents and dogs (Meyer et al. 1999; Bodkin et al. 2003a,b; Ortmeyer et al. 2005).

There are also species differences in the effects of $\mathrm{K}-111$ in healthy animals. K-111 altered lipid levels in metabolically normal rats to a similar extent to that seen with bezafibrate, with nearly maximal lipid reductions obtained with the lowest dose of $\mathrm{K}-111$ administered (1.5 mg/kg per day) (Meyer et al. 1999). In contrast, K-111 did not alter TG levels in healthy cynomolgus monkeys, which is consistent with the regulatory effect of PPAR alfa on lipid metabolism (Schäfer et al. 2004). The elevation of beta-oxidation enzymes, leading to enhancement of fatty acid catabolism, is likely to partially explain the lipidaltering potency of K-111 (Meyer et al. 1999; Schäfer et al. 2004). As previously observed for fibrates, the excessive enhancement of beta-oxidation enzymes by $\mathrm{K}-111$ in rats that leads to liver weight increase is not evident in primates, where modest increases in beta oxidation of up to three-fold similar to that seen in guinea-pigs and dogs were detected (Meyer et al. 1999; Schäfer et al. 2004).

\section{Cardiac metabolism and function}

PPAR alfa is highly expressed in the heart but very little is known as to how PPAR ligands affect cardiac function. In-vitro experiments on rat cardiomyocytes have indicated that $\mathrm{K}-111$ inhibits the cardiac activity of the PPAR target lipoprotein lipase by a posttranscriptional and posttranslational mechanism, reducing the availability of fatty acid products for tissue utilization (Carroll \& Severson 2001). In support of these data, K-111 leads to normalization of the altered cardiac metabolism (reduced glucose use, elevated fatty acid oxidation, and higher endogenous triacylglycerol content) characteristic of the $\mathrm{db} / \mathrm{db}$ mouse model by increasing the rates of cardiac glycolysis and myocardial glucose oxidation in the $\mathrm{db} / \mathrm{db}$ mouse models of diabetes by 1.7and 2.3-fold, respectively (Aasum et al. 2002). However, these changes are not observed in control animals, suggesting that the metabolic alterations reflect indirect mechanisms related to an improvement in diabetic status (Aasum et al. 2005). In addition, $\mathrm{K}-111$ did not have any effect on mechanical cardiac function in the $\mathrm{db} / \mathrm{db}$ model (Aasum et al. 2002, 2005).

\section{Bodyweight}

A dose-dependent decrease in bodyweight has been observed in all studies of obese rhesus monkeys (Bodkin et al. 2003a, Schäfer et al. 2004; Ortmeyer et al. 2005). In a dose-escalation study, compared with vehicle treatment there was significant weight loss of 2,4 , and $8 \%$ with $\mathrm{K}-111$ (1, 3, and $10 \mathrm{mg} / \mathrm{kg}$ day) $(P<0.001)$, accompanied by decreases in food intake of 10,17 , and $31 \%$, respectively (Bodkin et al. 2003a). These data are in contrast to the effect of fenofibrate in obese rhesus monkeys, in which bodyweight and food intake were not altered (Winegar et al. 2001). Significant weight reduction was also observed in healthy cynomolgus monkeys treated with $\mathrm{K}-11120 \mathrm{mg} / \mathrm{kg}$ per day for 13 weeks (13\% in males, $7 \%$ in females; $P$ value not provided in the paper) compared with vehicle control, with less pronounced effects at lower doses (Schäfer et al. 2004). In rodents, there was no increase (and in some studies a decrease) in bodyweight associated with K-111 (Pill \& Kühnle 1999; Aasum et al. 2002, 2005). In a comparative study of the effect of 4 weeks' treatment with $\mathrm{K}-111$ (1.5 to $12.5 \mathrm{mg} / \mathrm{kg}$ per day) or bezafibrate ( 25 or 75 $\mathrm{mg} / \mathrm{kg}$ per day) in healthy rats, bodyweight gain was significantly lower in the $\mathrm{K}-11112.5 \mathrm{mg} / \mathrm{kg}$ per day group and there was a tendency for lower values at 3 and $6 \mathrm{mg} / \mathrm{kg}$ per day, compared with controls, whereas values for both bezafibrate groups were similar to those in the control group (Pill \& Kühnle 1999).

\section{Insulin resistance}

In rodent models of type 2 diabetes with different genetic backgrounds (ob/ob, db/db and yellow KK mice, obese fa/fa Zucker rats) that confer a range of abnormalities of insulin metabolism, hyperglycemia and hyperinsulinemia were improved markedly with administration of K-111 (Pill \& Kühnle 1999). These data are consistent with initial in-vitro studies. In a comparative study of K-111 and troglitazone in yellow KK mice, improvements in glucose and insulin levels were greater with K-111 and achieved at lower doses than with troglitazone (Pill \& Meyer 1999). In studies 
in obese rhesus monkeys, K-111 administered over a range of doses and time periods significantly improved hyperinsulinemia and increased glucose uptake, confirming the beneficial effects on insulin sensitivity observed in rodents (Bodkin et al. 2003a,b; Schäfer et al. 2004). However, K-111 does not alter blood glucose in normoglycemic rodents or primates, indicating that hypoglycemia is unlikely to be a problem should $\mathrm{K}-111$ be administered to patients with the metabolic syndrome in the absence of hyperglycemia (Pill \& Kühnle 1999; Schäfer et al. 2004).

The mechanism of action of $\mathrm{K}-111$ in improving whole body insulin sensitivity has been examined in obese rhesus monkeys (Bodkin et al. 2003b; Ortmeyer et al. 2003, 2005). K-111 significantly reduces skeletal muscle TG content in obese rhesus monkeys and it is suggested that this reduction, secondary to an increase in fatty acid oxidation, leads to an increase in total glycogen synthase activity and subsequent improved insulin sensitivity (Ortmeyer et al. 2003, 2005). Glucose tolerance and beta-cell acute insulin response are not significantly affected by K-111 administration (Bodkin et al. 2003b). Rather, K-111's contribution to improving the metabolic syndrome includes mitigating insulin resistance.

\section{Pharmacokinetics and toxicity}

The study by Meyer et al. (1999) included a pharmacokinetic study of K-111 (day 22 of a 28-day administration period) in dogs and rats. In rats, $\mathrm{K}-111$ has a half-life of 2 hours whereas in dogs, the long half-life (40 hours) leads to high systemic exposure even at $1.5 \mathrm{mg} / \mathrm{kg}$ per day and a pretoxicity study indicated that doses $\geq 4 \mathrm{mg} / \mathrm{kg}$ per day should be regarded as toxic. Pharmacokinetic parameters determined after a single administration of $\mathrm{K}-111$ in mice, rats, dogs, and monkeys are consistent with these data, indicating a short half-life for mice, rats, and monkeys, even in the case of high dosing whereas a long half-life was seen in dogs (Pill \& Meyer 1999).

$\mathrm{K}-111$ was well tolerated in the pharmacologic dose range tested in rodent species (Pill \& Kühnle 1999). No adverse effects or signs of toxicity have been reported in obese monkeys (Bodkin et al. 2003a; Schäfer et al. 2004).

\section{Resource utilization}

Lifestyle interventions including diet and moderate physical activity can reduce the risk of developing type 2 diabetes by as much as $40-60 \%$ and at least half of all diabetes cases would be eliminated if weight gain in adults could be prevented (IDF 2005a). A reduction of $5-10 \%$ in bodyweight is sufficient to significantly improve comorbidities associated with obesity. Although lifestyle interventions do not incur drug costs, their successful implementation and adoption require time and resource allocation, including the development and application of strategies designed to optimize patient cooperation and continued participation in following diet and exercise programs.

An important aspect of managing the burden of the metabolic syndrome is the accurate identification of patients so that appropriate lifestyle and/or pharmacologic interventions can be initiated. Physicians and other healthcare professionals who are aware of the clustering of several risk factors within individuals are in a good position to ensure that all identified risk factors are quantified and treated to minimize subsequent cardiovascular risk and the development of diabetes. Addressing elements of the syndrome that have multiple deleterious consequences is clearly of major importance.

A single agent that impacts simultaneously and significantly on several aspects of the metabolic syndrome has the potential to have both clinical and economic advantages. However, such an agent must meet certain criteria for such a potential to be fulfilled. Firstly, the metabolic syndrome is heterogeneous and individual patients will vary in the combination and extent of their symptoms. Patients who are likely to benefit most from treatment with $\mathrm{K}-111$ are those with multiple metabolic abnormalities. However, to widen the eligibility for treatment with $\mathrm{K}-111$, it will need to be demonstrated that administering $\mathrm{K}-111$ to normalize some components of the syndrome (e.g. reducing bodyweight, improving the lipid profile) does not impact adversely on another parameter (e.g. unwanted induction of hypoglycemia). Second, the selectivity of K-111 for PPAR alfa means that its insulin-sensitizing and lipid normalization properties have to be at least equivalent to those associated with PPAR gamma or PPAR-alfa/gamma agonists but with a superior side-effect profile. Third, any evidence that $\mathrm{K}-111$ has additional pleiotropic effects such as those associated with diabetes medications and statins will be important in understanding its mode of action and applicability in the treatment of other conditions.

The ultimate test of K-111's economic benefit will be the demonstration that it significantly reduces morbidity and mortality associated with the metabolic syndrome to a greater extent and/or at lower cost than the combination of agents currently available for treating dyslipidemia and insulin resistance. However, in the shorter term, its use will be justified if it can be shown that using $\mathrm{K}-111$ reduces the need for polypharmacy without compromising efficacy.

\section{Drug profile}

Insulin resistance is more common in overweight individuals (McLaughlin et al. 2003). Ameliorating the pathology associated with insulin resistance by stimulating the PPAR-alfa pathway is an attractive strategy because of beneficial effects on the lipid profile and inflammation that occur in addition to improving glucose homeostasis. Agents with high specificity for PPAR alfa, such as $\mathrm{K}-111$, have the potential to decrease the cardiovascular risk associated with the metabolic syndrome in a superior manner to the currently available fibrates. Although the data for K-111 are limited to preclinical studies, the observation of marked improvements in lipid profiles, hyperinsulinemia, and obesity in nonhuman primates with features of the metabolic syndrome are encouraging. In addition, the almost uniform pharmacologic responses to $\mathrm{K}-111$ observed in obese rhesus monkeys with varied genetic background and pathophysiology is consistent 
with studies in rodents and suggest that the action of $\mathrm{K}-111$ is independent of the nature of the metabolic disturbance (Schäfer et al. 2004).

In the longer term, it will be important to assess the relative merits of K-111 versus PPAR-alfa/gamma dual agonists (glitazars) that are currently under investigation for treating diabetes and the metabolic syndrome. For example, approval of muraglitazar for the treatment of type 2 diabetes was recommended by a Food and Drug Administration advisory panel in September 2005. However, in a marked number of patients, muraglitazar causes fluid retention that has the potential to lead to congestive heart failure (Buse et al. 2005).

The most robust endpoint for future studies of $\mathrm{K}-111$ would clearly be outcomes studies measuring cardiovascular events, but these require several years of follow-up of a large population of patients. However, studies using surrogate endpoints (e.g. measuring lipid profiles) whose normalization has already been shown to reduce cardiovascular morbidity and mortality will also provide important information. Indeed, the complexity and number of metabolic pathways that are dysregulated in the metabolic syndrome and that could be affected by K-111 treatment (Fig. 1) make it desirable for a broad spectrum of variables (e.g. relating to inflammation, vascular function, hypertension, and lipids) to be included in addition to primary endpoints.

Whatever definition of the metabolic syndrome is chosen for future studies, there will always be a certain degree of heterogeneity among study patients, with individual patients varying in which and how many of the designated criteria for the

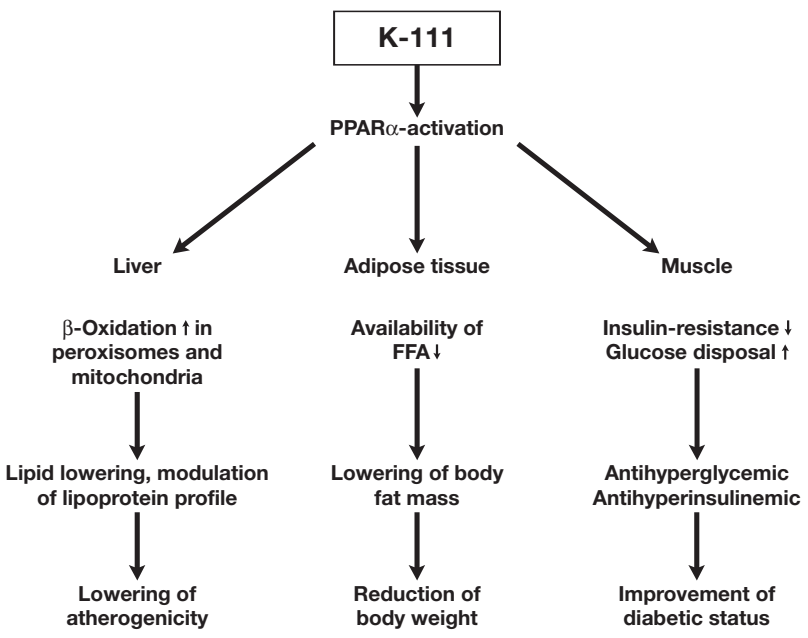

Fig. 1 | Putative mechanism of action of $\mathrm{K}-111$ and its expected impact on the therapy of metabolic disturbance. FFA, free fatty acids; PPAR, peroxisome proliserator-activated receptor. (Cardiovascular Drug Reviews by Pill J \& Meyer K. Copyright 1999 by Neva Press Inc. Reproduced with permission of Neva Press Inc. in the format Journal via Copyright Clearance Center) metabolic syndrome are met. In addition, it is not known whether different combinations of metabolic syndrome components confer the same cardiovascular risk. To minimize this, it would seem appropriate to design trials such that the spread of relevant baseline characteristics is kept to a minimum or at least controlled for so that there is sufficient power in the study to allow multivariate or predetermined subgroup analyses.

In summary, clinical trials of $\mathrm{K}-111$ are awaited to determine whether its preclinical potential is realized in patients with the metabolic syndrome.

\section{References}

Aasum E, Belke DD, Severson DL, et al. Cardiac function and metabolism in type 2 diabetic mice after treatment with BM 17.0744, a novel PPAR-alpha activator. Am J Physiol Heart Circ Physiol. 2002;283:H949-H957.

Aasum E, Cooper M, Severson DL, Larsen TS. Effect of BM 17.0744, a PPARalpha ligand, on the metabolism of perfused hearts from control and diabetic mice. Can J Physiol Pharmacol. 2005;83:183-190.

Abbasi F, Brown BW Jr, Lamendola C, McLaughlin T, Reaven GM. Relationship between obesity, insulin resistance, and coronary heart disease risk. J Am Coll Cardiol. 2002;40:937-943.

ADA (American Diabetes Association). Standards of medical care in diabetes. Diabetes Care. 2004;27(Suppl. 1):S15-S35.

Athyros VG, Ganotakis ES, Elisaf M, Mikhailidis DP. The prevalence of the metabolic syndrome using the National Cholesterol Educational Program and International Diabetes Federation definitions. Curr Med Res Opin. 2005;21:1157-1159.

Ayyobi AF, Brunzell JD. Lipoprotein distribution in the metabolic syndrome, type 2 diabetes mellitus, and familial combined hyperlipidemia. Am J Cardiol. 2003;92(4A):27J-33J.

Balkau B, Charles MA, Drivsholm T, et al; European Group for the study of Insulin Resistance (EGIR). Frequency of the WHO metabolic syndrome in European cohorts, and an alternative definition of an insulin resistance syndrome. Diabetes Metab. 2002;28:364-376.

Ballantyne CM, Olsson AG, Cook TJ, Mercuri MF, Pedersen TR, Kjekshus J. Influence of low high-density lipoprotein cholesterol and elevated triglyceride on coronary heart disease events and response to simvastatin therapy in 4S. Circulation. 2001;104:3046-3051.

Bellosta S, Ferri N, Arnaboldi L, Bernini F, Paoletti R, Corsini A. Pleiotropic effects of statins in atherosclerosis and diabetes. Diabetes Care. 2000;23(Suppl. 2):B72-B78.

Berger JP, Akiyama TE, Meinke PT. PPARs: therapeutic targets for metabolic disease. Trends Pharmacol Sci. 2005;26:244-251.

Bodkin NL, Pill J, Meyer K, Hansen BC. The effects of K-111, a new insulinsensitizer, on metabolic syndrome in obese prediabetic rhesus monkeys. Metab Res. 2003a;35:617-624.

Bodkin NL, Ortmeyer HK, Hansen BC. Improvement of the metabolic syndrome by a PPAR-alfa activator, K-111, through mitigation of insulin resistance and dyslipidemia rather than improved glucose tolerance and $\beta$-cell hyperresponsiveness. Diabetologia. 2003b;46(Suppl. 2) (Abstract 846).

Brousseau ME, Schaefer EJ, Wolfe ML, et al. Effects of an inhibitor of cholesteryl ester transfer protein on HDL cholesterol. $N$ Engl J Med. 2004;350:1505-1515.

Brown BG, Zhao XQ, Chait A, et al. Simvastatin and niacin, antioxidant vitamins, or the combination for the prevention of coronary disease. $\underline{\mathrm{N} \mathrm{Engl} \mathrm{J}}$ Med. 2001;345:1583-1592.

Buchanan TA, Xiang AH, Peters RK, et al. Preservation of pancreatic beta-cell function and prevention of type 2 diabetes by pharmacological treatment of insulin resistance in high-risk hispanic women. Diabetes. 2002;51:2796-2803. 
Buse JB, Rubin CJ, Frederich R, et al. Muraglitazar, a dual (alfa/gamma) PPAR activator: a randomized, double-blind, placebo-controlled, 24-week monotherapy trial in adult patients with type 2 diabetes. Clin Ther. 2005;27:1181-1195.

Carroll R, Severson DL. Peroxisome proliferator-activated receptor-alpha ligands inhibit cardiac lipoprotein lipase activity. Am J Physiol Heart Circ Physiol. 2001;281:H888-H894.

CDC (Centers for Disease Control and Prevention). National diabetes fact sheet. General information and national estimates on diabetes in the United States, 2005. Atlanta, GA: US Department of Health and Human Services, Centers for Disease Control and Prevention; 2005.

Chobanian AV, Bakris GL, Black HR, et al. Seventh report of the Joint National Committee on Prevention, Detection, Evaluation and Treatment of High Blood Pressure. Hypertension. 2003;42:1206-1252.

Cohen JD, Eberly LE, Prineas R, Vasquez G. The influence of the metabolic syndrome on 24-year mortality among middle-aged men in the Multiple Risk Factor Intervention Trial (MRFIT). J Am Coll Cardiol. 2003;41(Suppl. A):291A (Abstract 845-1).

Conroy RM, Pyorala K, Fitzgerald AP, et al; SCORE Project Group. Estimation of ten-year risk of fatal cardiovascular disease in Europe: the SCORE project. Eur Heart J. 2003;24:987-1003.

De Backer G, Ambrosioni E, Borch-Johnsen K, et al. European guidelines on cardiovascular disease prevention in clinical practice. Third Joint Task Force of European and Other Societies on Cardiovascular Disease Prevention in Clinical Practice. Eur Heart J. 2003;24:1601-1610.

de Ferranti SD, Gauvreau K, Ludwig DS, Neufeld EJ, Newburger JW, Rifai N. Prevalence of the metabolic syndrome in American adolescents: findings from the Third National Health And Nutrition Examination Survey. Circulation. 2004;110:2494-2497.

Delerive P, Fruchart J-C, Staels B. Peroxisome proliferator-activated receptors in inflammation control. J Endocrinol. 2001;169:453-459.

Després J-P, Lemieux I, Prud'homme D. Treatment of obesity: need to focus on high risk abdominally obese patients. BMJ. 2001;322:716-720.

Drake AJ, Smith A, Betts PR, Crowne EC, Shield JP. Type 2 diabetes in obese white children. Arch Dis Child. 2002;86:207-208.

Duncan GE, Li SM, Zhou XH. Prevalence and trends of a metabolic syndrome phenotype among U.S. adolescents, 1999-2000. Diabetes Care. 2004;27:2438-2443.

Durbin RJ. Thiazolidinedione therapy in the prevention/delay of type 2 diabetes in patients with impaired glucose tolerance and insulin resistance. Diabetes Obes Metab. 2004;6:280-285.

Eckel RH, Grundy SM, Zimmet PZ. The metabolic syndrome. Lancet. 2005;365:1415-1428.

Einhorn D, Reaven GM, Cobin RH, et al. American College of Endocrinology position statement on the insulin resistance syndrome. Endocr Pract. 2003;9:237-252.

ESH/ESC (European Society of Hypertension-European Society of Cardiology) Guidelines Committee. 2003 European Society of Hypertension-European Society of Cardiology guidelines for the management of arterial hypertension. J Hypertens. 2003;21:1011-1053.

Falkner B, Hassink S, Ross J, Gidding S. Dysmetabolic syndrome: multiple risk factors for premature adult disease in an adolescent girl. Pediatrics. 2002;110:e14.

Ford ES, Giles WH, Dietz WH. Prevalence of the metabolic syndrome among US adults: findings from the Third National Health And Nutrition Examination Survey. JAMA. 2002;287:356-359.

Ford ES, Giles WH. A comparison of the prevalence of the metabolic syndrome using two proposed definitions. Diabetes Care. 2003;26:575-581.

Frick MH, Elo O, Haapa K, et al. Helsinki Heart Study: primary-prevention trial with gemfibrozil in middle-aged men with dyslipidemia. Safety of treatment, changes in risk factors, and incidence of coronary heart disease. N Engl J Med. 1987;317:1237-1245.

Fröhlich M, Imhof A, Berg G, et al. Association between C-reactive protein and features of the metabolic syndrome: a population-based study. Diabetes Care. 2000;23:1835-1839.
Girman CJ, Rhodes T, Mercuri M, et al; 4S Group and the AFCAPS/TexCAPS Research Group. The metabolic syndrome and risk of major coronary events in the Scandinavian Simvastatin Survival Study (4S) and the Air Force/Texas Coronary Atherosclerosis Prevention Study (AFCAPS/TexCAPS). Am J Cardiol. 2004;93:136-141.

Grundy SM, Brewer HB Jr, Cleeman JI, Smith SC Jr, Lenfant C; American Heart Association; National Heart, Lung, and Blood Institute. Definition of metabolic syndrome: report of the National Heart, Lung, and Blood Institute/American Heart Association conference on scientific issues related to definition. Circulation. 2004a;109:433-438.

Grundy SM, Hansen B, Smith SC Jr, Cleeman JI, Kahn RA; American Heart Association; National Heart, Lung, and Blood Institute; American Diabetes Association. Clinical management of metabolic syndrome: report of the American Heart Association/National Heart, Lung, and Blood Institute/American Diabetes Association conference on scientific issues related to management. Circulation. 2004b;109:551-556.

Hu G, Qiao Q, Tuomilehto J, Balkau B, Borch-Johnsen K, Pyorala K; DECODE Study Group. Prevalence of the metabolic syndrome and its relation to allcause and cardiovascular mortality in nondiabetic European men and women. Arch Intern Med. 2004;164:1066-1076.

Hunninghake DB, Ballantyne CM, Maccubbin DL, Shah AK, Gumbiner B, Mitchel YB. Comparative effects of simvastatin and atorvastatin in hypercholesterolemic patients with characteristics of metabolic syndrome. Clin Ther. 2003;25:1670-1686.

IDF (International Diabetes Federation). The IDF consensus worldwide definition of the metabolic syndrome. Brussels: International Diabetes Federation; 2005a. Available at: http://www.idf.org/webdata/docs/IDF_metasyndrome_definition_pdf (accessed September 2005).

IDF (International Diabetes Federation) Clinical Guidelines Task Force. Global guideline for type 2 diabetes. Brussels: International Diabetes Federation; 2005b. Available at: http://www.idf.org (accessed September 2005).

Isomaa B, Almgren P, Tuomi T, et al. Cardiovascular morbidity and mortality associated with the metabolic syndrome. Diabetes Care. 2001;24:683-689. James PT, Rigby N, Leach R; International Obesity Task Force. The obesity epidemic, metabolic syndrome and future prevention strategies. Eur $\mathrm{J}$ Cardiovasc Prevent Rehabil. 2004;11:3-8.

Kahn R, Buse J, Ferrannini E, Stern M. The metabolic syndrome: time for a critical appraisal. Joint statement from the American Diabetes Association and the European Association for the Study of Diabetes. Diabetes Care. 2005;28:2289-2304.

Kaufman FR. Type 2 diabetes mellitus in children and youth: a new epidemic. J Pediatr Endocrinol Metab. 2002;15(Suppl. 2):737-744.

Klein S, Burke LE, Bray GA, et al; American Heart Association Council on Nutrition, Physical Activity, and Metabolism. Clinical implications of obesity with specific focus on cardiovascular disease: a statement for professionals from the American Heart Association Council on Nutrition, Physical Activity, and Metabolism: endorsed by the American College of Cardiology Foundation. Circulation. 2004;110:2952-2967.

Knowler WC, Barrett-Connor E, Fowler SE, et al; Diabetes Prevention Program Research Group. Reduction in the incidence of type 2 diabetes with lifestyle intervention or metformin. N Engl J Med. 2002;346:393-403.

L'Italien G, Ford I, Shepherd J. The metabolic syndrome is an independent predictor of cardiac events in WOSCOPS males. J Am Coll Cardiol. 2003;41(Suppl. A):291A (Abstract 845-3).

Lakka HM, Laaksonen DE, Lakka TA, et al. The metabolic syndrome and total and cardiovascular disease mortality in middle-aged men. JAMA. 2002a;288:2709-2716.

Lakka HM, Lakka TA, Tuomilehto J, Salonen JT. Abdominal obesity is associated with increased risk of acute coronary events in men. Eur Heart $\mathrm{J}$. 2002b;23:706-713.

Lee YH, Pratley RE. The evolving role of inflammation in obesity and the metabolic syndrome. Curr Diab Rep. 2005;5:70-75. 
Liao JK. Beyond lipid lowering: the role of statins in vascular protection. Int J Cardiol. 2002;86:5-18.

Madej A, Okopien B, Kowalski J, et al. Effects of fenofibrate on plasma cytokine concentrations in patients with atherosclerosis and hyperlipoproteinemia IIb. Int J Clin Pharmacol Ther. 1998;36:345-349.

Malik S, Wong ND, Franklin SS, et al. Impact of the metabolic syndrome on mortality from coronary heart disease, cardiovascular disease, and all causes in United States adults. Circulation. 2004;110:1245-1250.

Manninen V, Tenkanen L, Koskinen P, et al. Joint effects of serum triglyceride and LDL cholesterol and HDL cholesterol concentrations on coronary heart disease risk in the Helsinki Heart Study. Implications for treatment. Circulation. 1992;85:37-45.

Matsuzawa Y, Funahashi T, Kihara S, Shimomura I. Adiponectin and metabolic syndrome. Arterioscler Thromb Vasc Biol. 2004;24:29-33.

McLaughlin T, Abbasi F, Cheal K, Chu J, Lamendola C, Reaven G. Use of metabolic markers to identify overweight individuals who are insulin resistant. Ann Intern Med. 2003;139:802-809.

Meyer K, Völkl A, Endele R, Kühnle H-F, Pill J. Species differences in induction of hepatic enzymes by BM 17.0744, an activator of peroxisome proliferatoractivated receptor alpha (PPARalpha). Arch Toxicol. 1999;73:440-450.

Miyachi $\mathrm{H}$. Recent progress in research on peroxisome proliferator-activated receptor alpha-selective ligands. IDrugs. 2004;7:746-754.

Mora S, Blumenthal RS, Yanek LR, Moy TF, Becker LC, Becker DM. Elevated $\mathrm{C}$-reactive protein in high-risk asymptomatic individuals is strongly associated with the metabolic syndrome. J Am Coll Cardiol. 2003;41(Suppl. A):292A (Abstract 845-5).

National Heart, Lung, and Blood Institute. Clinical guidelines on the identification, evaluation, and treatment of overweight and obesity in adults: the evidence report. Bethesda, MA: National Institutes of Health, National Heart, Lung, and Blood Institute; September 1998. NIH Publication No. 98-4083.

NCEP ATP III. Expert Panel on Detection, Evaluation, and Treatment of High Blood Cholesterol in Adults. Executive Summary of The Third Report of The National Cholesterol Education Program (NCEP) Expert Panel on Detection, Evaluation, and Treatment of High Blood Cholesterol In Adults (Adult Treatment Panel III). JAMA. 2001;285:2486-2497.

Nesto R. C-reactive protein, its role in inflammation, type 2 diabetes and cardiovascular disease, and the effects of insulin-sensitizing treatment with thiazolidinediones. Diabet Med. 2004;21:810-817.

Nieuwdorp M, Stroes ES, Meijers JC, Buller H. Hypercoagulability in the metabolic syndrome. Curr Opin Pharmacol. 2005;5:155-159.

Ninomiya JK, L'Italien G, Criqui MH, Whyte JL, Gamst A, Chen RS. Association of the metabolic syndrome with history of myocardial infarction and stroke in the Third National Health And Nutrition Examination Survey. Circulation. 2004;109:42-46.

Orchard TJ, Temprosa M, Goldberg R, et al; Diabetes Prevention Program Research Group. The effect of metformin and intensive lifestyle intervention on the metabolic syndrome: the Diabetes Prevention Program randomized trial. Ann Intern Med. 2005;142:611-619.

Ortmeyer H, Bodkin N, Hansen B. A PPAR-alpha activator, K-111, improves skeletal muscle insulin sensitivity in obese rhesus monkeys. Diabetologia. 2003;46(Suppl. 2):A292 (Abstract 845).

Ortmeyer HK, Adall Y, Marciani KR, et al. Skeletal muscle glycogen synthase subcellular localization: effects of insulin and PPAR-alpha agonist (K-111) administration in rhesus monkeys. Am J Physiol Regul Integr Comp Physiol. 2005;288:R1509-R1517.

Park Y-W, Zhu S, Palaniappan L, Heshka S, Carnethon MR, Heymsfield SB. The metabolic syndrome. Prevalence and associated risk factor findings in the US population from the Third National Health And Nutrition Examination Survey, 1988-1994. Arch Intern Med. 2003;163:427-436.

Pill J, Kühnle H-F. BM 17.0744: a structurally new antidiabetic compound with insulin-sensitizing and lipid-lowering activity. Metabolism. 1999;48:34-40.

Pill J, Meyer K. Reduction of risk factors for cardiovascular complications by BM 17.0744. Cardiovasc Drug Rev. 1999;17:246-264.

Prineas RJ, Folsom AR, Kaye SA. Central adiposity and increased risk of coronary artery disease mortality in older women. Ann Epidemiol. 1993;3:35-41.
PROactive (PROspective pioglitAzone Clinical Trial In macroVascular Events) Steering Committee. Results of the PROactive study. Presented at: European Association for the Study of Diabetes annual meeting; September 10-15, 2005; Athens, Greece. Available at: http://www.proactive-results.com (accessed October 10, 2005).

Rajagopalan R, lyer S, Khan M. Effect of pioglitazone on metabolic syndrome risk factors: results of double-blind, multicenter, randomized clinical trials. Curr Med Res Opin. 2005;21:163-172.

Reaven GM. Banting lecture 1988. Role of insulin resistance in human disease. Diabetes. 1988;37:1595-1607.

Ridker PM, Buring JE, Cook NR, Rifai N. C-reactive protein, the metabolic syndrome, and risk of incident cardiovascular events: an 8-year follow-up of 14719 initially healthy American women. Circulation. 2003;107:391-397.

Ridker PM, Wilson PW, Grundy SM. Should C-reactive protein be added to metabolic syndrome and to assessment of global cardiovascular risk? Circulation. 2004;109:2818-2825.

Rimm EB, Stampfer MJ, Giovannucci E, et al. Body size and fat distribution as predictors of coronary heart disease among middle-aged and older US men. Am J Epidemiol. 1995;141:1117-1127.

Robins SJ, Rubins HB, Faas FH, et al; Veterans Affairs HDL Intervention Trial. Insulin resistance and cardiovascular events with low HDL cholesterol: the Veterans Affairs HDL Intervention Trial (VA-HIT). Diabetes Care. 2003;26:1513-1517.

Rosenson RS, Tangney CC. Antiatherothrombotic properties of statins: implications for cardiovascular event reduction. JAMA. 1998;279:1643-1650.

Rubins HB, Robins SJ, Collins D, et al. Gemfibrozil for the secondary prevention of coronary heart disease in men with low levels of high-density lipoprotein cholesterol. Veterans Affairs High-density Lipoprotein Cholesterol Intervention Trial Study Group. N Engl J Med. 1999;341:410-418.

Sakkinen PA, Cushman M, Psaty BM, et al. Relationship of plasmin generation to cardiovascular disease risk factors in elderly men and women. Arterioscler Thromb Vasc Biol. 1999;19:499-504.

Sattar N, Gaw A, Scherbakova O, et al. Metabolic syndrome with and without $\mathrm{C}$-reactive protein as a predictor of coronary heart disease and diabetes in the West of Scotland Coronary Prevention Study. Circulation. 2003;108:414-419.

Schäfer SA, Hansen BC, Völkl A, Fahimi D, Pill J. Biochemical and morphological effects of $\mathrm{K}-111$, a peroxisome proliferator-activated receptor (PPAR)alpha activator, in non-human primates. Biochem Pharmacol. 2004;68:239-251

Sowers JR. Effects of statins on the vasculature: implications for aggressive lipid management in the cardiovascular metabolic syndrome. Am J Cardiol. 2003;91(Suppl.):14B-22B.

Staels B, Koenig W, Habib A, et al. Activation of human aortic smooth-muscle cells is inhibited by PPARalpha but not by PPARgamma activators. Nature. 1998;393:790-793.

Stern MP, Williams K, Gonzalez-Villalpando C, Hunt KJ, Haffner SM. Does the metabolic syndrome improve identification of individuals at risk of type 2 diabetes and/or cardiovascular disease? Diabetes Care. 2004;27:2676-2681.

Tenenbaum A, Motro M, Fisman EZ, Tanne D, Boyko V, Behar S. Bezafibrate for the secondary prevention of myocardial infarction in patients with metabolic syndrome. Arch Intern Med. 2005;165:1154-1160.

Tenkanen L, Mänttäri M, Manninen V. Some coronary risk factors related to the insulin resistance syndrome and treatment with gemfibrozil. Experience from the Helsinki Heart Study. Circulation. 1995;92:1779-1785.

Tsimihodimos V, Miltiadous G, Daskalopoulou SS, Mikhailidis DP, Elisaf MS. Fenofibrate: metabolic and pleiotropic effects. Curr Vasc Pharmacol. 2005;3:87-98.

UKPDS 33. Intensive blood-glucose control with sulphonylureas or insulin compared with conventional treatment and risk of complications in patients with type 2 diabetes (UKPDS 33). UK Prospective Diabetes Study (UKPDS) Group. Lancet. 1998;352:837-853.

UKPDS 34. Effect of intensive blood-glucose control with metformin on complications in overweight patients with type 2 diabetes (UKPDS 34). UK Prospective Diabetes Study (UKPDS) Group. Lancet. 1998;352:854-865. 


\section{K-111 | emerging therapy review}

Weiss R, Dziura J, Burget TS, et al. Obesity and the metabolic syndrome in children and adolescents. N Engl J Med. 2004;350:2362-2374.

Whitworth JA; World Health Organization, International Society of Hypertension Writing Group. 2003 World Health Organization (WHO)/International Society of Hypertension (ISH) statement on management of hypertension. $\mathbf{J}$ Hypertens. 2003;21:1983-1992.

Wild S, Roglic G, Green A, Sicree R, King H. Global prevalence of diabetes: estimates for the year 2000 and projections for 2030. Diabetes Care. 2004;27:1047-1053.

Williams BM, Poulter NR, Brown MJ, et al; British Hypertension Society. Guidelines for management of hypertension: report of the fourth working party of the British Hypertension Society, 2004-BHS IV. J Hum Hypertens. 2004;18:139-185.

Wilson PW, D'Agostino RB, Levy D, Belanger AM, Silbershatz H, Kannel WB. Prediction of coronary heart disease using risk factor categories. Circulation. 1998;97:1837-1847.

Winegar DA, Brown PJ, Wilkison WO, et al. Effects of fenofibrate on lipid parameters in obese rhesus monkeys. J Lipid Res. 2001;42:1543-1551.

WHO (World Health Organization) consultation. Definition, diagnosis and classification of diabetes mellitus and its complications. Part 1, diagnosis and classification of diabetes mellitus. Geneva: World Health Organization Department of Noncommunicable Disease Surveillance; 1999. WHO/NCD/NCS/99.2.
WHO (World Health Organization). Factsheet on diabetes: the cost of diabetes. Geneva: World Health Organization; 2002a.

WHO (World Health Organization). The world health report 2002. Reducing risks, promoting healthy life. Geneva: World Health Organization; 2002b. Available at: http://www.who.int/whr/2002/en/whr02_en.pdf (accessed February 10, 2006).

WHO (World Health Organization). Factsheet on obesity and overweight. Geneva: World Health Organization; 2003.

Wysocki J, Belowski D, Kalina M, Kchanski L, Okopien B, Kalina Z. Effects of micronized fenofibrate on insulin resistance in patients with metabolic syndrome. Int J Clin Pharmacol Ther. 2004;42:212-217.

Yki-Järvinen H. Thiazolidinediones. N Engl J Med. 2004;351:1106-1118.

Correspondence: Margaret Duggan-Keen, Core Medical Publishing, Mere House, Brook Street, Knutsford, Cheshire WA16 8GP, UK or at editor@coreevidence.com 